\title{
Peningkatan Pemahaman Citra Tubuh Melalui Edukasi Online pada Wanita Usia Subur
}

\author{
Laras Sitoayu ${ }^{1 *}$, Yolanda Krisna Dewi ${ }^{2}$, Juliana ${ }^{3}$, Renita Febriana ${ }^{4}$, Rizkita \\ Windhiyaningrum ${ }^{5}$, Lintang Purwara Dewanti ${ }^{6}$, Nanda Aula Rumana ${ }^{7}$ \\ 1* Program Studi Pendidikan Profesi Dietsien, Universitas Esa Unggul, Jl. Arjuna Utara No.9, Jakarta Barat, \\ Daerah Khusus Ibukota Jakarta 11510, Indonesia \\ 2,3,4,5,6,7 Program Studi Ilmu Gizi, Universitas Esa Unggul, Jl. Arjuna Utara No.9, Jakarta Barat, Daerah \\ Khusus Ibukota Jakarta 11510, Indonesia \\ Corresponding Email: laras@esaunggul.ac.id ${ }^{1}$
}

\section{Histori Artikel:}

Diterima 21 December 2021; Diterima dalam bentuk revisi 13 Januari 2022; Diterima 3 Februari 2022; Diterbitkan 7 Februari 2022. Semua hak dilindungi oleh Lembaga Peneltiian dan Pengabdian Masyarakat (LPPM) AMIK Indonesia.

\begin{abstract}
Abstrak
Remaja putri sebagai WUS menentukan masa depan anak dan keluarganya, membutuhkan perhatian khusus daripada mengalami masalah gizi. Masalah gizi yang sering dialami oleh remaja putri adalah persepsi tubuh yang negatif, yang pada akhirnya berujung pada gangguan makan dan masalah status gizi. Melalui program pengabdian masyarakat ini bertujuan untuk meningkatkan kesadaran dan pengetahuan remaja putri tentang body image agar tidak mengalami masalah gizi. Edukasi dilakukan secara online, dan dapat dijadikan sebagai metode alternatif pendidikan gizi bagi remaja putri. Kegiatan ini dilaksanakan pada siswa SMK Mutiara 17 Agustus Bekasi dengan melibatkan siswa kelas X dan XI Farmasi. Hasil pendidikan menunjukkan bahwa ada peningkatan pengetahuan tentang persepsi tubuh pada remaja putri.
\end{abstract}

Kata Kunci: Gadis Remaja; Citra Tubuh; Pendidikan Gizi.

\section{Pendahuluan}

WUS menjadi salah satu kelompok usia rawan gizi di masyarakat karena penentu masa depan keluarga ketika sudah berkeluarga. Ketika WUS terkena masalah gizi, maka tidak dipungkiri dapat melahirkan anak dengan masalah gizi atau bahkan menerapkan pola asuh gizi yang salah pula baik pada anak ataupun keluarga. Masa remaja merupakan masa transisi seseorang dari anak-anak menjadi dewasa, pada masa ini remaja terutama remaja putri mulai sadar akan identitas diri dan lebih banyak memberikan perhatian yang besar terhadap bentuk dan citra tubuh [1]. Hasil penelitian yang dilakukan pada 120 siswa SMAN Jakarta menyatakan 19.2\% remaja mengalami distorsi citra tubuh [2]. Penelitian yang dilakukan di SMAN Bogor menunjukan 94.8\% siswi memiliki persepsi tubuh negatif, dan dipengaruhi oleh faktor lingkungan seperti orang tua $(90.9 \%)$, teman $(80.5 \%)$ dan media massa (68.8\%) [3]. Salah satu WUS yang memiliki risiko tinggi terkena masalah gizi adalah WUS yang masih menempuh pendidikan menengah atas, salah satunya remaja putri pada SMK Mutiara 17 Agustus Bekasi.

SMK Mutiara 17 Agustus Bekasi merupakan salah satu sekolah di kawasan Kota Bekasi tepatnya berada di wilayah Harapan Baru, Bekasi Utara. Sebagai salah satu sekolah di kawasan Bekasi Utara, SMK Mutiara 17 Agustus memiliki lokasi yang cukup strategis dan dapat dijangkau melalui berbagai alat transportasi, seperti mobil dan motor. Selain itu, SMK Mutiara 17 Agustus memiliki kejuruan di bidang kesehatan seperti analisis kesehatan dan farmasi, sehingga diharapkan dapat menjadi contoh yang baik untuk sekolah sejenis, tentunya dengan menerapkan pola hidup sehat bagi warga sekolah. Terlebih lagi siswi SMK Mutiara 17 Agustus adalah remaja. 
Masa remaja merupakan periode Window of Opportunity dalam kehidupan, karena merupakan masa transisi anak-anak dan dewasa, dan akan sangat menentukkan kematangan mereka di masa depan. Sehingga perhatian khusus perlu diberikan pada remaja agar status gizi dan kesehatan optimal dapat dicapai. Sehingga sangat penting memperhatikan kesehatan terutama gizi WUS pada siswi SMK Mutiara 17 Agustus. Remaja putri mementingkan penampilan fisik dengan bentuk tubuh proposional, sehingga menyebabkan kurang percaya diri dan selalu menilai dirinya melalui kaca mata orang lain seperti teman dan lingkungan sekitar [4].

Saat ini banyak remaja memiliki masalah terhadap diri sendiri, terutama dalam menilai citra tubuh (body image) terutama pada remaja wanita, mereka cenderung tidak puas terhadap tubuh mereka dan memiliki body image negatif [5]. Persepsi tubuh (body image) adalah kumpulan sikap indivisu yang disadari dan tidak disadari terhadap tubuhnya, merupakan persepsi dari tubuh seseorang yang dibentuk secara emosional dan bisa berubah seiring dengan perubahan suasana hati, pengalaman, maupun lingkungan. Seseorang yang memiliki persepsi tubuh positif akan puas terhadap dirinya sendiri, nyaman dan percaya diri. Seseorang yang memiliki persepsi tubuh negatif menganggap tubuhnya tidak menarik, merasa malu, dan tidak percaya diri [6,7]. Body image yang negatif, akan mempengaruhi pola makan seorang remaja, mereka cenderung mengurangi asupan/eating disorders sehingga pada akhirnya menyebabkan masalah gizi [8].

Dengan kegiatan pengabdian masyarakat ini diharapkan dapat mengatasi masalah gizi yang ada. Edukasi ini disampaikan secara online menggunakan media edukasi yang disampaikan secara komprehensif sehingga meskipun dalam keadaan pandemi dan pembelajaran jarak jauh (PJJ), siswi SMK Mutiara 17 Agustus tetap teredukasi dan dapat menerapkan pola hidup sehat dan bergizi.

\subsection{Tujuan Kegiatan}

Tujuan kegiatan pengabdian yang dilakukan adalah untuk meningkatkan kesadaran dan pengetahuan remaja putri tentang body image agar tidak mengalami masalah gizi. Edukasi dilakukan secara online, dan dapat dijadikan sebagai metode alternatif pendidikan gizi bagi remaja putri.

\subsection{Manfaat Kegiatan}

Dengan kegiatan pengabdian masyarakat ini diharapkan dapat mengatasi masalah gizi yang ada. Edukasi ini disampaikan secara online menggunakan media edukasi yang disampaikan secara komprehensif sehingga meskipun dalam keadaan pandemi dan pembelajaran jarak jauh (PJJ), siswi SMK Mutiara 17 Agustus tetap teredukasi dan dapat menerapkan pola hidup sehat dan bergizi.

\section{Realisasi Kegiatan}

\subsection{Bentuk Kegiatan \& Jadwal, Serta Tempat Kegiatan \\ a. Metode Pelaksanaan Kegiatan}

Kegiatan pengabdian masyarakat ini dilakukan di SMK Mutiara 17 Agustus Bekasi, dengan sasaran siswi kelas X dan XI di sekolah. Kegiatan intervensi MISI RATU dilakukan pada Rabu, 07 April 2021 pukul 19.00-20.00 WIB. Siswi yang mengikuti kegiatan MISI Ratu berjumlah 26 Orang. Panitia terdiri dari 4 orang anggota, dimana setiap anggota memiliki tugas masing-masing, seperti menjadi moderator, pembicara materi, membuat google form untuk absensi, pre-test dan post-test serta membagikan link google form yang telah dibuat dan seksi dokumentasi.

Alur kegiatan program intervensi MISI RATU dilakukan secara virtual dengan menggunakan metode kuliah whatsapp (kulwap), mulai dari penggabungan siswi kelas X Farmasi dan XI Farmasi kedalam satu grup whatsapp, persiapan intervensi dan menginformasikan metode intervensi dengan kulwap, selanjutnya pengisian link absensi, mengerjakan pre-test dengan waktu 10 menit, dilakukan intervensi program misi ratu dengan media buku saku digital dan penjelasan isi buku melalui chat. Setelah intervensi selesai, siswi mengerjakan post-test, selanjutnya dilakukan sesi tanya jawab. 


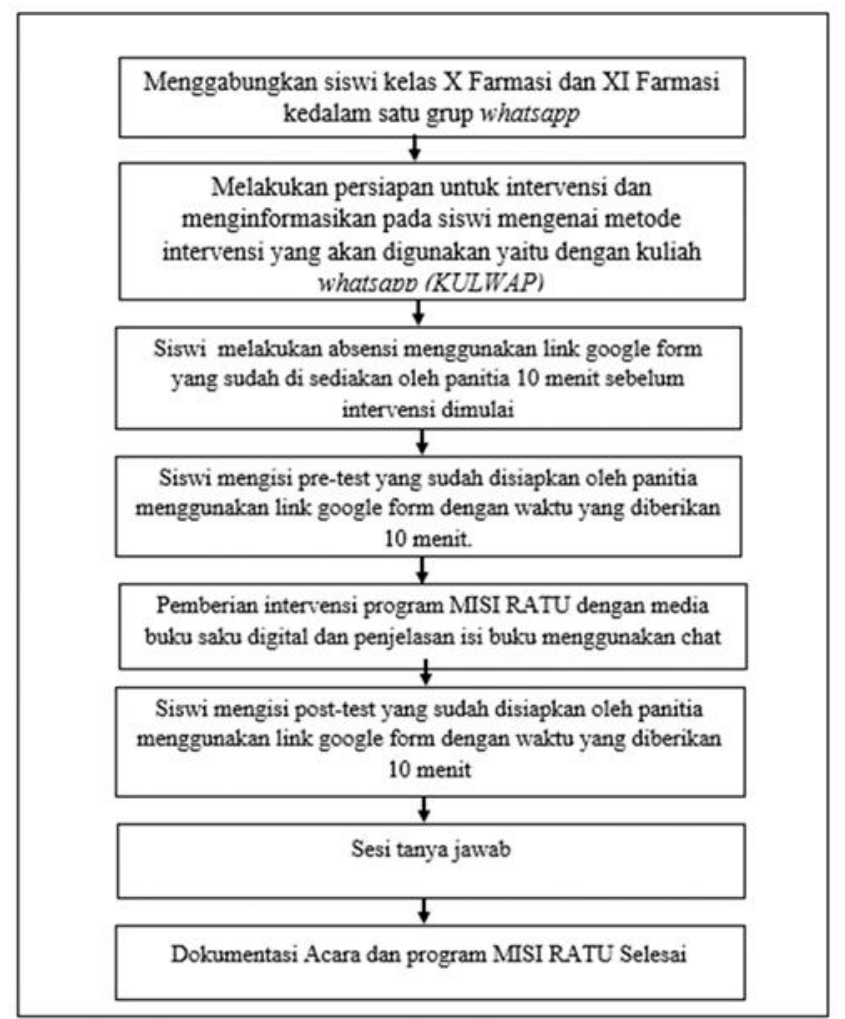

Gambar 1. Alur Kegiatan Program MISI RATU

\section{b. Waktu Efektif Pelaksanaan Kegiatan}

Kegiatan pengabdian masyarakat ini dilakukan di SMK Mutiara 17 Agustus Bekasi, dengan sasaran siswi kelas X dan XI di sekolah. Kegiatan intervensi MISI RATU dilakukan pada Rabu, 07 April 2021 pukul 19.00-20.00 WIB.

\section{c. Tempat Kegiatan}

Kegiatan pengabdian masyarakat ini dilakukan di SMK Mutiara 17 Agustus Bekasi, dengan sasaran siswi kelas X dan XI di sekolah.

\subsection{Hasil Pelaksanaan Pengabdian}

Kegiatan intervensi diawali dengan mengingatkan siswi terkait program MISI RATU yang akan dilaksanakan serta menggabungkan siswi dalam satu grup whatsapp, setelah memberikan informasi mengenai metode kuliah whatsapp dan mempersiapkan untuk intervensi misi ratu. Acara dimulai dengan pembukaan oleh moderator dengan menyapa siswi yang hadir, selanjutnya siswi diwajibkan mengisi absensi dengan link google form yang sudah disiapkan oleh panitia, 10 menit sebelum acara dimulai. Program dapat dikatakan berhasil apabila penilaian indikator sudah baik atau mencapai target yaitu kehadiran dan adanya peningkatan pengetahuan.

Selanjutnya siswi melakukan pengisian pre-test dengan link yang sudah disiapkan dengan waktu pengisian selama 10 menit dengan jumlah pertanyaan sebanyak 10 soal yang berisikan mengenai materi yang terdapat dalam buku saku digital. Soal pertama yaitu mengenai faktor yang berkontribusi terhadap body image negatif, soal kedua yaitu perbedaan body image, soal ketiga dan delapan yaitu dampak dari body image yang negatif, soal keempat yaitu mengenai faktor yang mempengaruhi body image, soal kelima yaitu mengenai pengertian body image, soal keenam yaitu berisikan tentang cara memperbaiki body image, soal ketujuh yaitu mengenai aspek body image, soal kesembilan mengenai waktu olahraga yang baik untuk meningkatkan suasana psikologi dan mental, dan soal yang kesepuluh yaitu berisikan tentang citra tubuh yang positif. Setelah siswi mengerjakan pre-test maka acara dilanjutkan kepada intervensi program MISI RATU. 
Pelaksanaan program MISI RATU menggunakan media buku saku digital (gambar 2) dengan waktu kurang lebih sekitar 20 menit dan metode penjelasan isi buku saku digital dengan diiringi respon siswi melalui pesan chat di grup whatsapp. Media buku saku dibuat menarik dengan Bahasa yang mudah dipahami oleh remaja puteri, agar dapat diterapkan dalam kehidupan sehari-hari.

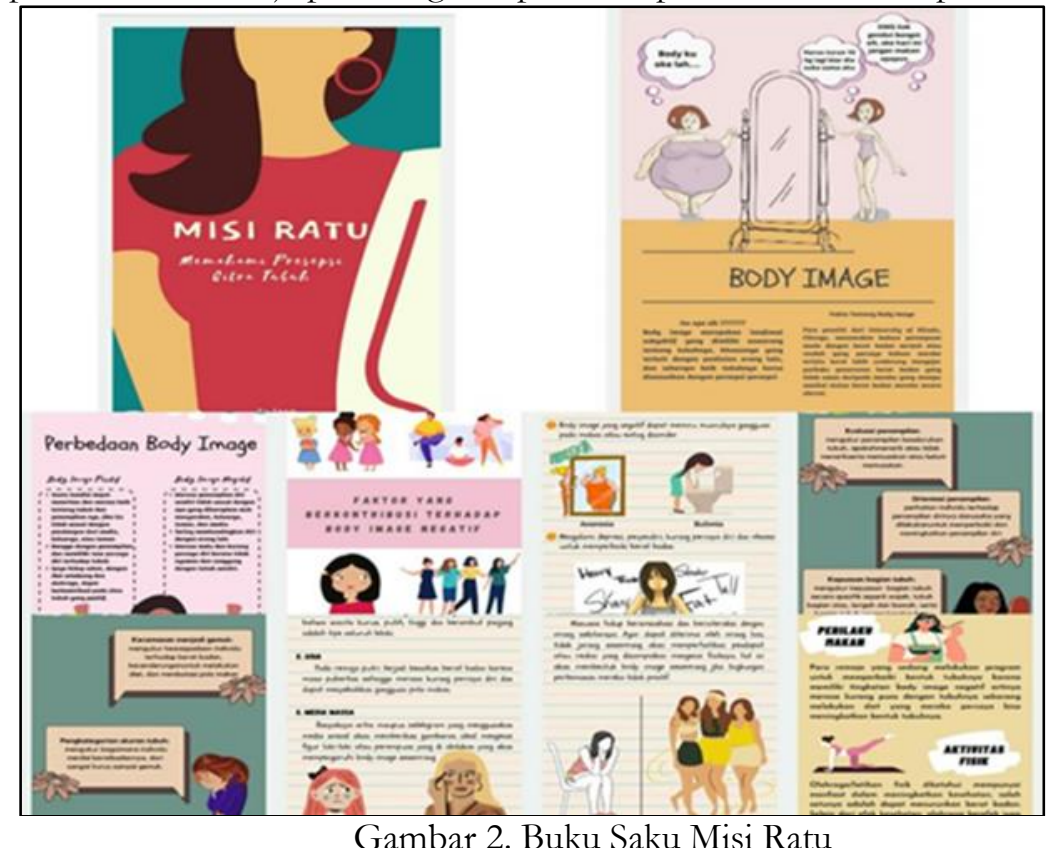

Setelah selesai penjelasan dengan buku saku digital, dilanjutkan dengan pengisian post-test yang dipandu oleh moderator dengan menggunakan link yang sudah dibuat. Waktu pengerjaan post-test selama 10 menit dengan soal yang sama seperti pre-test. Setelah mengerjakan post-test selanjutnya siswi diberikan kesempatan bertanya pada sesi diskusi dan tanya jawab dengan waktu kurang lebih 15 menit. Setelah selesai sesi diskusi acara dilanjutkan dengan pengisian kesan dan pesan dalam program terakhir MISI RATU. Pada sesi tanya jawab hanya ada satu siswi yang bertanya mengenai materi yang dibahas.

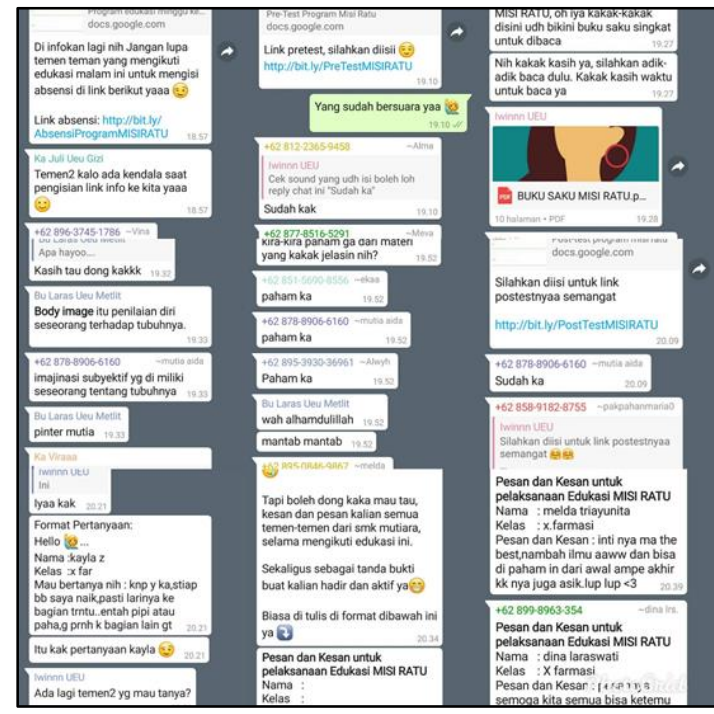

Gambar 3. Intervensi Misi Ratu

Setelah intervensi MISI RATU selesai didapatkan hasil yaitu, persentase kehadiran sebesar 81\% (26 orang siswi dari total 32 siswi) sehingga untuk persentase kehadiran mencapai target $>50 \%$. Pada saat kegiatan intervensi berlangsung partisipasi siswi masih kurang dan cenderung 
diam serta lambat respon dalam grup chat intervensi, untuk mengatasi hal tersebut tim berupaya untuk mencairkan suasana dan memaparkan materi dengan lebih santai dengan diiringi sapa salam akrab, setelah itu siswi mulai aktif dan antusias dengan program yang sedang berjalan.

\subsection{Diskusi}

Pengetahuan pada siswi mengalami peningkatan dilihat dari hasil pre-test dan post-test yang dilakukan secara online dengan google form, dengan hasil rata-rata nilai pre-test yaitu 63 poin dan hasil rata-rata nilai post-test 89 poin maka terjadi peningkatan sebesar 26 poin. Berdasarkan hasil tersebut membuktikan bahwa whatsapp bukan hanya sebagai media komunikasi namun dapat juga digunakan sebagai media edukasi (9). Sebagai siswi remaja, saat pandemi dengan metode PJJ dituntut untuk dapat menggunakan whatsapp sebagai salah satu media dalam mendukung pembelajaran. Whatsapp dipilih sebagai media yang baik untuk pembelajaran karena fiturnya yang lengkap, mudah dalam penggunaannya dan sangat sering digunakan oleh remaja. Kemudahan untuk terkoneksi secara langsung menjadi daya tarik aplikasi messaging ini sehingga pengguna semakin heterogen dan tersebar, oleh karena itu whatsapp juga memberikan kontribusi bagi bidang pendidikan (10).

Dari 10 soal yang diberikan, terdapat 5 soal yang memiliki jawaban benar paling sedikit, pertama pertanyaan tentang faktor yang mempengaruhi body image hanya sebanyak $32 \%$ siswi menjawab dengan benar, yang kedua pertanyaan tentang cara memperbaiki body image hanya sebanyak 46\% siswi menjawab dengan benar, yang ketiga pertanyaan tentang aspek terhadap body image hanya sebanyak $46 \%$ siswi menjawab dengan benar, yang keempat pertanyaan mengenai dampak body image negatif hanya sebanyak $35 \%$ dan yang terakhir yaitu pertanyaan tentang lama waktu olahraga yang baik untuk meningkatkan suasana psikologi dan mental hanya sebanyak 21\% siswi menjawab dengan benar. Hal ini menggambarkan masih banyaknya ketidaktahuan siswi mengenai body image dan akan berpengaruh kepada body image dirinya. Seperti hasil penelitian yang menyatakan siswa sekolah banyak yang memiliki citra diri buruk, harga diri buruk, ideal diri buruk, peran diri buruk dan identitas diri buruk (11). Persepsi tubuh yang tidak baik pada remaja putri dapat mengakibatkan kecemasan menjadi gemuk dan pada akhirnya mengalami gangguan makan (12).

Setelah dilakukan intervensi dengan media buku saku digital, terdapat peningkatan pengetahuan yang dilihat dari pengerjaan post-test. Pada pengerjaan soal post-test meningkat dengan hasil rata-rata siswi dapat menjawab pertanyaan dengan benar. Pemilihan media edukasi yang menarik dapat meningkatkan persepsi body image pada remaja (13). Dengan adanya edukasi kepada remaja menggunakan media yang menarik, diharapkan dapat meningkatkan pengetahuan dan persepsi mengenai body image.

\section{Tinjauan Hasil yang dicapai}

Edukasi gizi dalam jaringan (daring) menggunakan whatsapp berhasil meningkatkan pengetahuan pada remaja putri mengenai body image. Penting dilakukan kegiatan edukasi serupa untuk terus meng-update ilmu gizi pada remaja meskipun dalam masa pandemi.

\section{Ucapan Terima Kasih}

Terima kasih kepada SMK Mutiara 17 Agustus Bekasi atas dukungan atas terselenggaranya kegiatan ini. Dan juga siswi kelas X dan XI Farmasi atas partisipasinya pada kegiatan edukasi gizi. 


\section{Daftar Pustaka}

[1] Pusparini P, Refdanita R, Maigoda TC, Briawan D. Studi Kualitatif Persepsi Citra Tubuh Remaja yang Kurus dan Gemuk Serta Upaya untuk Mencapai Tubuh Ideal Pada Siswi SMA Negeri 1 Kota Bogor. J Kesehat. 2013;6(1):15-28.

[2] Handayani M. Faktor-Faktor yang Mempengaruhi Distorsi Citra Tubuh Siswa SMAN I Pamulang Tahun 2009. UIN Syarief Hidayatullah; 2009.

[3] Septiana; Briawan. Penggunaan Metode Body Shape Questionnaire (BSQ) dan Figure Rating Scale (FRS) untuk Pengukuran Persepsi Tubuh Remaja Perempuan. Gizi Indones. 2010;33(1):29-36.

[4] Denich AU, Ifdil I. Konsep Body image Remaja Putri. J Konseling dan Pendidik. 2015;3(2):55.

[5] Alidia F. Body image Siswa Ditinjau Dari Gender. Tarbawi J Ilmu Pendidik. 2018;14(2):79.

[6] Paratmanitya, Y; Hadi HS. Citra tubuh, asupan makan, dan status gizi wanita usia subur pranikah. J Gizi Klin Indones. 2012;8:126-34.

[7] Wilfley, DE; Bishop, ME; Wilson G et al. Classification of eating disorders: toward DSM-V. Int J Eat Disord. 2007;40:123-9.

[8] Syifa RSA, Pusparini P. Persepsi tubuh negatif meningkatkan kejadian eating disorders pada remaja usia 15-19 tahun. J Biomedika dan Kesehat. 2018;1(1):18-25.

[9] Sartika. Kegunaan whatsapp sebagai media informasi dan media pembelajaran pada mahasiswa ilmu komunikasi STISIP persada bunda. Medium. 2018;6(2):15-26.

[10] Zakirman, Rahayu C. Popularitas WhatsApp Sebagai Media Komunikasi dan Berbagi Informasi Akademik Mahasiswa. Shaut al-Maktabah J Perpustakaan, Arsip dan Dokumentasi [Internet]. 2018;10(1):27-38. Available from: https://rjfahuinib.org/ejournal/index.php/shaut\%0Ahttps://rjfahuinib.org/index.php/sha ut/article/view/7/6

[11] Suwargarini R, Mubin MF. Gambaran Psikologis: Konsep Diri Pada Anak Usia Sekolah Dasar Di Wilayah Banjir Rob Kelurahan Bandarharjo Semarang Utara. J Keperawatan Anak. 2014;2(2):124-32.

[12] Kurniawan MY, Briawan D, Caraka RE. Persepsi Tubuh dan Gangguan Makan pada Remaja (Body image Perception and Eating Disorders in Adolescents). J Gizi Klin Indones. 2015;11(3):105-14.

[13] Masitah R, Pamungkasari EPS. Pengaruh Pendidikan Gizi Dengan Video Animasi Terhadap Persepsi Body image Remaja. J Nurs Public Heal. 2018;5(1):88-94. 